\title{
Correlation of serum magnesium levels in eclampsia with pritchard and single dose magnesium sulphate regimen
}

\author{
Shreya M. S., Nayana D. H.* \\ Department of Obstetrics and Gynecology, Rajarajeshwari Medical College and Hospital, Bengaluru, India \\ Received: 03 July 2019 \\ Accepted: 08 August 2019 \\ *Correspondence: \\ Dr. Nayana D. H., \\ E-mail: drshreyatharun @gmail.com \\ Copyright: (c) the author(s), publisher and licensee Medip Academy. This is an open-access article distributed under \\ the terms of the Creative Commons Attribution Non-Commercial License, which permits unrestricted non-commercial \\ use, distribution, and reproduction in any medium, provided the original work is properly cited.
}

\begin{abstract}
Background: Magnesium sulphate is anticonvulsant of choice for eclampsia. Single dose magnesium sulphate therapy was tried for the management of Eclampsia and Imminent Eclampsia considering the low body mass index of Indian population.

Methods: A prospective interventional study comprising of total 80 patients having either eclampsia or imminent eclampsia, to whom the Pritchard or a single dose $\mathrm{MgSO}_{4}$ was given alternatively in a tertiary hospital from October 2014 to October 2017. Serum magnesium levels, maternal and perinatal outcome and recurrence of convulsions were evaluated using Student- t test and chi square test.

Results: Mean Serum Magnesium levels in eclampsia and imminent eclampsia group at 0 min, 30 min, 4 hours in Pritchard regimen were $1.96 \mathrm{mg} / \mathrm{dl}, 5.85 \mathrm{mg} / \mathrm{dl}, 4.68 \mathrm{mg} / \mathrm{dl}$ while in single dose regimen it was $1.78 \mathrm{mg} / \mathrm{dl}, 462 \mathrm{mg} / \mathrm{dl}$, $3.63 \mathrm{mg} / \mathrm{dl}$ respectively. Those who received Pritchard regimen showed higher level of Serum magnesium levels at 30 minutes and 4 hours than those receiving single dose. By applying T-test it was found that there is a significant difference in serum magnesium levels range in both group but no statistical difference in the control of convulsions in both groups.

Conclusions: With increased and almost widespread use of magnesium sulfate in obstetrics there has been concerns regarding its safety. In the study, although P-values are not significant because of small sample size, there is considerable difference in serum magnesium levels $30 \mathrm{~min}$ and 4 hours, recurrence of convulsions and maternal morbidity between Pritchard regimen and single dose regimen. The goal which was achieved with Pritchard regimen previously, now can be achieved with single dose regimen in Indian women. Single dose magnesium sulphate is safe and effective in controlling convulsions with improved maternal and perinatal outcome.
\end{abstract}

Keywords: Eclampsia, Imminent eclampsia, Low dose regimen, Pre-eclampsia, Pritchard regimen, Recurrent convulsions, Single dose magnesium sulphate

\section{INTRODUCTION}

Hypertensive disorders of pregnancy are a leading cause of direct maternal mortality. ${ }^{1}$ The global incidence of preeclampsia and eclampsia are $2.16 \%$ and $0.28 \%$, respectively. ${ }^{2}$ In India, the incidence of eclampsia ranges from 1 in 500 to 1 in $30 .^{3}$ Following collaborative
Eclamptic trial, magnesium sulphate is regarded as the agent of choice for control and prevention of eclamptic convulsions. ${ }^{4}$ Dose-related toxicity of magnesium sulphate is a major concern. ${ }^{4,5}$ Side effects of $\mathrm{MgSO}_{4}$ are rare but include disappearance of patellar reflex (8-10 $\mathrm{mEq} / \mathrm{l})$, blurred vision, slurred speech (9- $12 \mathrm{mEq} / \mathrm{l})$, Respiratory paralysis (12 $\mathrm{mEq} / \mathrm{l})$, prolonged PR, QT, 
QRS (10-15 mEq/l), cardiac arrest $(30 \mathrm{mEq} / \mathrm{l})$. Fetal effects include neurological and neuromuscular depression, hyporeflexia, decreases FHR variability, low APGAR scores etc.

Pritchard showed that serum magnesium concentration required for eclampsia prevention or treatment should be higher than normal serum levels, and its therapeutic concentration should be between 4 and $7 \mathrm{mEq} / \mathrm{L} .{ }^{6}$ Hence Pritchard suggested that high dose standard regimen, which was standardized for Western women needs dose alteration for small weights of Indian women. Numerous low dose regimens were described due to concern about toxicity considering small weights of Indian population. ${ }^{7-12}$ Begum $\mathrm{R}$ et al used a low dose magnesium sulphate regimen for Eclampsia and concluded that half of the standard dose of magnesium sulphate would to be sufficient to control convulsions effectively and serum levels of magnesium remained lower than levels which produce toxicity. ${ }^{7}$

But in developing countries like India, particularly in rural areas the picture is radically different where eclampsia may present for treatment after having had many fits at home. Sibai has mentioned the important characteristics of an anticonvulsant drug. ${ }^{13}$ Those were simplicity of administration and monitoring in clinical setting and familiarity of physicians and nurses working in obstetric units with its pharmacokinetics as well as pharmaco-dynamics. They are important because the margin of error for under doing or overdosing might prove life threatening for both mother and her foetus, especially in busy obstetric units or referral hospitals. Low dose magnesium sulphate regime is very simple to administer and easy to monitor and is as effective as Pritchard's regime. As there has been controversy regarding varying opinion by various workers regarding the appropriate anticonvulsant dose in addition there is considerable controversy regarding the therapeutic levels of magnesium needed to prevent convulsions.

Therefore, in the study it was sought to compare serum magnesium levels of eclamptic pregnant women receiving Pritchard regimen with those treated with low dose regimen.

\section{METHODS}

The study was conducted in a tertiary care hospital, South India for a period of three years comprising of 80 patients. It was a prospective interventional comparative study involving 80 women with eclampsia, to whom the Pritchard or a single dose magnesium sulphate regimen was administered alternatively. The study was approved by the hospital's Ethics Research Committee, written informed consent in the women's own language was obtained prior to drug administration. 80 cases of antepartum/ intrapartum/ postpartum eclampsia were included in the study. Cases not willing to participate in study, those who had already received either magnesium sulphate or other anticonvulsants before admission or contraindication for magnesium sulphate like respiratory depression, renal failure, heart block, severe hepatitis, hypersensitivity, myasthenia gravis, myocardial damage were excluded from the study.

Cases were then enrolled in study after written informed consent. detailed history was followed with general, physical, systemic and obstetrical examination. History was elicited from attendants if patient was brought in a post ictal state or unconscious state. Following initial resuscitation investigations like complete hemogram including peripheral smear with bloodgrouping, LDH levels, liver function tests, kidney function tests, coagulation profile, fundus examination and urine analysis for proteinuria were done.

Group 1 received standard Pritchard regimen- loading dose $4 \mathrm{~g}$ (20ml of 20\%) IV over 8-10 Minutes followed by $10 \mathrm{~g}(20 \mathrm{ml}$ of $50 \%) \mathrm{IM} 5 \mathrm{~g}$ in each buttock. After loading dose, maintenance dose was given $5 \mathrm{~g}(10 \mathrm{ml}$ of $50 \%)$ is given every 4 hours at alternate buttocks. Presence of knee reflex, respiratory rate $>14 /$ minute, urine output $>100 \mathrm{ml}$ were monitored, magnesium sulphate was given until 24 hours after delivery.

Group 2 received single dose magnesium sulphate $4 \mathrm{~g}$ (20 $\mathrm{ml}$ of 20\%) IV over 8-10 minutes followed by $4 \mathrm{~g}$ of $50 \%$ magnesium sulphate solution intramuscularly. No further maintenance dose was given. If convulsions recur after 30 minutes loading dose, $2 \mathrm{~g}$ IV of magnesium sulphate $(10 \mathrm{ml}$ of $20 \%)$ is given over 2 minutes. Evidence of impending magnesium toxicity was detected by observing respiratory rate, patellar reflexes and urinary output four hourly.

Antihypertensives like Tab. labetalol $100 \mathrm{mg}$ was given twice or thrice or tab nifedipine $10 \mathrm{mg}$ was given twice or thrice Bolus inj. labetalol injection was given when the diastolic blood Pressure $>110 \mathrm{~mm}$ of $\mathrm{Hg}$, with initial dose of $20 \mathrm{mg}$ intravenously; later increased to $40 \mathrm{mg}$ after 20minutes or further to $80 \mathrm{mg}$ if diastolic blood pressure $>110 \mathrm{~mm}$ of $\mathrm{Hg}$. The aim was to bring the diastolic blood pressure $\leq 100 \mathrm{~mm}$ of $\mathrm{Hg}$. $5 \mathrm{ml}$ blood was drawn from antecubital vein in a sterile syringe at $0,30 \mathrm{~min}$ and 4 hours after administration of magnesium sulphate. Blood was allowed to clot at room temperature for 30 minutes later was centrifuged at $3000 \mathrm{rpm}$ for 10 minutes. Serum magnesium was estimated by atomic absorption spectrophotometer (AA-7000) $\cdot{ }^{14}$ Each sample was stored at $0.4^{\circ} \mathrm{C}$ later were analysed within week of collection. To analyse the data, Students' t-test was employed to assess the significance of difference between two groups. Chisquare test and p-value of $<0.05$ was considered as statistically significant. The serum magnesium levels were compared between groups 1 and 2 at 0,30 min and 4hours during magnesium sulphate therapy. The readings of serum magnesium levels of each subject were recorded in the proforma in addition to demographic profile and relevant investigations. 


\section{Obstetric management}

After stabilizing of patient, termination of pregnancy was undertaken in all cases and based on bishops score induction was done using Foleys, prostaglandin gel, tab. misoprostol. ARM and oxytocin infusion was used for augmentation of labour. Labour was carefully monitored. LSCS was done if there was any obstetric indication or uncontrolled convulsions. After delivery patient was observed for 48 - 72 hours in the high dependency unit and post - operative ward and followed up till the discharge.

\section{RESULTS}

In three - year, study period there were 80 cases of which 40 received standard Pritchard regimen and the remaining 40 received single dose regimen alternatively.

Table 1: Age distribution of the subjects.

\begin{tabular}{|lll|}
\hline Age in years & Eclampsia (80) \\
\hline$<15$ & Pritchard (40) & Single (40) \\
\hline $15-20$ & 0 & 0 \\
\hline $21-29$ & $2(5 \%)$ & $1(2.5 \%)$ \\
\hline $30-35$ & $30(75 \%)$ & $29(72.5 \%)$ \\
\hline$>35$ & $8(20 \%)$ & $10(25 \%)$ \\
\hline
\end{tabular}

It was observed from Table 1 that, in Pritchard 30 (75\%) patients and in single dose regimen $29(72.5 \%)$ patients were between 21-29 years. There were no patients $<15$ years and $>35$ years in both groups.

Table 2: Parity distribution of cases.

\begin{tabular}{|lll|}
\hline Gravidity & Pritchard (40) & Single dose (40) \\
\hline Primi & $24(60 \%)$ & $26(65 \%)$ \\
\hline G2-G3 & $14(35 \%)$ & $3(32.5 \%)$ \\
\hline G4 and above & $2(5 \%)$ & $1(2.5 \%)$ \\
\hline
\end{tabular}

Among 80 cases recruited $24 \quad(60 \%)$ cases were primigravida in Pritchard regimen group and single dose group 26(65\%). G2 - G3 patients were $14(35 \%)$ in Pritchard regimen group and single dose group3 (32.5\%). G4 and above patients were $2(5 \%)$ in Pritchard regimen group and single dose group $1(2.5 \%)$.

Table 3: Distribution of cases based on antenatal care.

\begin{tabular}{|lll|}
\hline Antenatal care & Pritchard (40) & Single dose (40) \\
\hline Booked & $5(12.5 \%)$ & $7(17.5 \%)$ \\
\hline Unbooked & $31(77.5 \%)$ & $28(70 \%)$ \\
\hline Booked outside & $4(10 \%)$ & $5(12.5 \%)$ \\
\hline
\end{tabular}

It was observed that past history of PIH was present in 4 patients belonging to G4 and above and 2 patients belonging to $\mathrm{G} 2$, G3. Mean age of study population was $23.11 \pm 1.66$ years. Most $(80 \%)$ were primigravida residing in rural communities who received little or no antenatal care and most of the cases were un-booked $(63.75 \%)$.

The subjects were categorised into 3 groups-registered in the hospital, outside registered and unbooked. Minimum of 3 antenatal visits was taken as criteria for determining registration status during course of gestation. Most of cases were unregistered 31 (77.5\%) in Pritchard regimen group and single dose group $28(70 \%)$.

The number of convulsions before admission to hospital varied from 3 to 6 . Most women were of small stature, with a mean height of $152 \pm 4.0 \mathrm{~cm}$, a mean weight of $46.7 \pm 4 \mathrm{~kg}$ and a mean body mass index of $21.5 \pm 1.5$.

Table 4: Distribution of cases based on type of Eclampsia.

\begin{tabular}{|lll|}
\hline $\begin{array}{l}\text { Type of } \\
\text { eclampsia }\end{array}$ & Pritchard (40) & $\begin{array}{l}\text { Single dose } \\
(40)\end{array}$ \\
\hline Antepartum & $30(77.5 \%)$ & $28(70 \%)$ \\
\hline Intrapartum & $1(2.5 \%)$ & 0 \\
\hline Postpartum & $8(20 \%)$ & $12(30 \%)$ \\
\hline
\end{tabular}

Majority had antepartum eclampsia (77.5\%) in group 1 and $70 \%$ in group 2.Mean gestational age in Group 1 was $32.5 \pm 2.7$ weeks and in Group 2 was $34.8 \pm 2.81$ weeks. Mean diastolic blood pressure was 112. \pm 10.66 and $98 \pm 12.28 \mathrm{mmHg}$ in the groups 1 and 2, respectively. Proteinuria was present in all the cases of study population. However, more noticeable among cases of Group $1(60.1 \%)$.

Table 5: Serum magnesium levels in both groups at different time points of therapy.

\begin{tabular}{|lll|}
\hline $\begin{array}{l}\text { Magnesium level } \\
\text { in mg/dl }\end{array}$ & \multicolumn{2}{c|}{ Eclampsia (80) Mean \pm SD } \\
& Pritchard(40) & Single (40) \\
\hline 0 minute & $1.96 \pm 0.24$ & $1.78 \pm 0.21$ \\
\hline 30 minutes & $5.85 \pm 1.05$ & $4.62 \pm 1.33$ \\
\hline 4 hours & $4.68 \pm 1.21$ & $3.63 \pm 0.70$ \\
\hline
\end{tabular}

Mean serum magnesium levels in Eclampsia and Imminent Eclampsia group at $0 \mathrm{~min}, 30 \mathrm{~min}, 4$ hours in Pritchard regimen were $1.96 \mathrm{mg} / \mathrm{dl}, 5.85 \mathrm{mg} / \mathrm{dl}, 4.68 \mathrm{mg} / \mathrm{dl}$ while in single dose regimen it was $1.78 \mathrm{mg} / \mathrm{dl}$, $4.62 \mathrm{mg} / \mathrm{dl}, 3.63 \mathrm{mg} / \mathrm{dl}$ respectively. Those who received Pritchard regimen showed higher level of mean serum magnesium levels at 30 minutes and $4 \mathrm{hrs}$ than those receiving single dose. Baseline serum magnesium levels at 0 minute in both groups did not show much difference in serum magnesium levels and $\mathrm{P}$ value was 0.199 which is not significant. Overall, the mean serum magnesium level at $30 \mathrm{~min}$ and 4 hours was significantly higher $(0 \mathrm{p}<0.05)$ in group 1 when compared to group 2. 
Maximum dose of magnesium sulphate was 40-50 grams in most of the cases of Groups 1 and in Group 2 was $8 \mathrm{gm}$. Both regimens were equally efficacious in control and prevention of convulsions $(96.6 \%$ vs $100 \%$, $\mathrm{p}=0.358)$. After 24 hours of magnesium sulphate therapy, there was a significant drop $(p<0.05)$ in proteinuria in both the groups compared to baseline. Recurrence occurred only in one case in pritchard regimen group and in two cases in single dose regimen. Following 24 hours of magnesium sulphate administration, there was decrease in the severity of edema was present in $35(85.7 \%)$ and $32(82.85 \%)$ cases of Group 1 and 2 respectively. This was statistically significant $(\mathrm{p}<0.001)$.

Mean DBP decreased by $20.7 \pm 2.1 \mathrm{mmHg}$ in Group 1 and $20 \pm 2.1 \mathrm{mmHg}$ in Group 2 after 24 hours of magnesium sulphate. Fall in DBP between both groups was not statistically significant. Feto-maternal outcomes were similar in both groups, there was no statistical significant difference in the CS rate in both groups $(40.9 \%$ vs. $45.8 \%, \mathrm{p}=0.112$ ). Maternal morbidity and perinatal outcomes were also comparable in both groups. Single case of mortality was encountered during the study in pritchard regimen group, however the cause of death was late referral of the patient and there was no magnesium toxicity in that patient.

Maternal complications like oliguria, knee jerk depression, induration at injection site were more in Pritchard regimen than single dose regimen. $\mathrm{P}$ value is 0.25 which is not significant.

\section{DISCUSSION}

The incidence of eclampsia in untreated preeclamptic women is approximately $3-4 \%$, while for those receiving magnesium sulphate therapy is $0.8-1 \% .^{5}$ The efficacy of magnesium sulphate for eclamptic convulsions has been well validated by numerous trials performed worldwide.

Eclampsia affects $0.2 \%$ to $0.5 \%$ of all deliveries. Incidence in the hospital was $2 \%$. The majority of cases were unbooked, coming from villages and did not have regular antenatal check-ups. Since many decades Pritchard regimen has been used however it is under constant discussion regarding the required dose of magnesium sulfate and its safety and therapeutic serum magnesium level. Standard regimen prescribed by pritchard was in accordance to average western women weight. Also Pritchard himself suggested that the dose of magnesium sulphate should be limited in women who are small.

Hence in India, standard Pritchard's regimen has been subjected to various modifications like Dhaka regimen, VIMS regimen, Suman and Sardesi regimen etc due to concerns over cost of treatme safety and limited patient to doctor ratio requiring regular and frequent monitoring of the patients who receive $\mathrm{MgSO}_{4}{ }^{8,15-17}$ But the main question was what should be the ideal dose. Therefore in present study serum magnesium levels of eclamptic pregnant women receiving Pritchard regimen was compared with those treated with low dose regimen.

Although it is a well-established fact that eclampsia and preeclampsia are more common in extremes of age none of the cases in the study was $<15$ or $>35$ years. ${ }^{6,18}$ Body mass index (BMI) is important factor determining the efficacy and toxicity of $\mathrm{MgSO}_{4}$, as seen in the study carried by Tudela et al, Jana et al. in Burdwan, India found that low dose $\mathrm{MgSO}_{4}$ (8g loading- $3 \mathrm{~g}$ IV and $5 \mathrm{~g}$ IM; followed by $2.5 \mathrm{~g}$ IM 4 hourly) was safe and effective for eclamptic women having low BMI. ${ }^{8,19}$ Similar to the study there was lower incidence of seizure recurrence and lower maternal mortality compared with the Collaborative Eclampsia Trial. ${ }^{4}$

Eclampsia was more common in the primigravida and in women of age group 21-30 years similar toSardesi and Suyajna DJ et al, and Biswas et al. ${ }^{8,18,20}$ Georgia A et al, refers that maternal age of $<20$ years is the strongest risk factor for Eclampsia higher incidence $<20$ years may be related to subnormal development of uterine vessles. ${ }^{18}$

Majority of cases presented with eclampsia at term in the study most cases were preterm ranging between 28-36 weeks. Antepartum eclampsia is commonest as shown by many studies which is comparable with the study which was seen in $70 \%$. $^{8,15-17,2-23}$

The normal serum magnesium levels vary from 1.6 to $2.1 \mathrm{mEq} / 1$. An IV dose of $4 \mathrm{~g}$ Magnesium sulphate causes an immediate elevation of Magnesium level from normal to 7 to $9 \mathrm{mEq} / \mathrm{L}$, subsequently due to intracellular transfer and renal elimination the concentration drops to 4 to 5 $\mathrm{mEq} / \mathrm{L}$ by one hour. By about 90 minutes $50 \%$ of the infused Magnesium move intracellular and by 4 hours about $50 \%$ are excreted in urine. Mean serum magnesium levels in those who received Pritchard regimen showed higher level of serum magnesium levels at 30 minutes and 4 hours than those receiving single dose. The baseline serum magnesium levels at 0 minute in both groups did not show much difference in serum magnesium levels. Since $50 \%$ of infused dose will be excreted when serum $\mathrm{Mg}$ exceeds $2 \mathrm{mg} / \mathrm{dl}$, it is justified to give single dose regimen. Also, women receiving single dose $\mathrm{MgSO}_{4}$ had significantly lower incidence of side effects (like absent knee jerk and decreased respiratory rate) than women receiving the standard Pritchard regime also such as tissue necrosis, abscess formation associated with repeated IM injections thus improving patient compliance in the study.

Recurrence rate was $1 \%$ out of 1158 patients who received Pritchard regimen in a study conducted by Sibai. ${ }^{13}$ In collaborative eclampsia trial recurrence rate was $5.7 \% .{ }^{4}$ In the study the recurrence rate with standard regimen was $2.5 \%$ and in group 2 was $5 \%$. The concept of using only the loading dose to control and prevent 
convulsions was first advocated by Boyd and Brower (28) but first detailed study was published in 2002 by Begum et al. ${ }^{25}$ Single dose regimen used in the study is advantageous for so many reasons. Firstly, it decreases the risk of magnesium sulphate toxicity since most patients would not need the maintenance doses. Clinical monitoring with Pritchard regimen that is eliciting patellar reflexes, counting respiratory rate and measuring urinary output would be done at a tertiary hospital where there are adequate health care facilities and supervision. But the same monitoring is a challenge especially at the district hospitals and primary health care centers of our country. Secondly, the cost of treatment using the single dose regimen is less compared to standard regimen and this would be a welcome in a poor resource developing country like ours. Another observation from this study that majority of eclamptic patients that would have a repeat fit will do so within one hour of the loading dose and thereby giving thehealth care worker an opportunity to identify those who would need additional maintenance doses.

The positive angle of the study lies in demonstration of safety and efficacy of single dose $\mathrm{MgSO}_{4}$ in parallel with the standard Pritchard regime. But the study has its limitations. Firstly, the number of cases included was very less as those with complications at admission, those who had already received $\mathrm{MgSO}_{4}$ outside and those with contraindications for $\mathrm{MgSO}_{4}$ were excluded and an economic analysis was not done of the two regimens.

\section{CONCLUSION}

With increased and almost widespread use of magnesium sulphate in obstetrics there has been concerns regarding its safety. In the study, although $\mathrm{P}$ values was not significant because of small sample size, there is considerable difference in serum magnesium levels 30 min and $4 \mathrm{hrs}$, recurrence of convulsions and maternal morbidity between Pritchard regimen and single dose regimen. The goal which was achieved with Pritchard regimen previously, now can be achieved with single dose regimen in Indian women. Single dose magnesium sulphate is safe and effective in controlling convulsions with improved maternal and perinatal outcome.

\section{Funding: No funding sources}

Conflict of interest: None declared

Ethical approval: The study was approved by the Institutional Ethics Committee

\section{REFERENCES}

1. Say L, Chou D, Gemmill A, Tunçalp Ö, Moller AB, Daniels J, et al. Global causes of maternal death: a WHO systematic analysis. Lancet Glob Health. 2014;2(6):323-33.

2. Abalos E, Cuesta C, Carroli G, Qureshi Z, Widmer $\mathrm{M}$, Vogel JP, et al. WHO multicountry survey on maternal and newborn health research network. preeclampsia, eclampsia and adverse maternal and perinatal outcomes: a secondary analysis of the World Health Organization multicountry survey on maternal and newborn health. BJOG. 2014;121(1):14-24.

3. Dutta DC. Hypertensive disorders in pregnancy. In: Konar H, editor. DC Dutta's Text Book of Obstetrics. 8th ed. New Delhi: Jaypee Brothers Medical Publishers (P) Ltd; 2015:268.

4. Duley L. The eclampsia trial collaborative group. which anticonvulsant for women with eclampsia?. evidence from the collaborative eclampsia trial. Lancet. 1995;345:1455-63.

5. Pritchard JA, Cunningham FG, Pritchard SA. The parkland memorial hospital protocol for treatment of eclampsia: evaluation of 245 cases. Am J Obstet Gynecol. 1984;148:951-63.

6. Duley L, Henderson- Smart D, Chou D: Magnesium sulphate versus phenytoin for eclampsia; Cohrane Database of Systemic Reviews. 2010;10:CD000128.

7. Begum R, Begum A, Johanson R, Ali MN, Akther S. A low dose ("Dhaka") magnesium sulphate regime for eclampsia'. Acta Obstet Gynecol Scand. 2001; 80(11):998-1002.

8. Jana N, Dasgupta S, Das AK, Santra D, Samanta B. Experience of a low-dose magnesium sulfate regimen for the management of eclampsia over a decade. Int J Gynaecol Obstet. 2013;122:13-7.

9. Sardesai S, Maira S, Patil A. Low dose magnesium sulphate therapy for eclampsia and imminent Eclampsia - regimen tailored for Indian women. J Obstet Gynecol India. 2003;53:546-50.

10. Shilva, Saha SC, Kalra J, Prasad R. Safety and efficacy of low-dose MgSO 4 in the treatment of eclampsia. Int J Gynaecol Obstet. 2007;97:150-1.

11. Bangal V, Kwatra A, Raghav S, Jadhav S. Low dose magnesium sulphate regime for Eclampsia. Pravara Med Rev 2009;4:13-5.

12. Mahajan NN, Thomas A, Soni RN, Gaikwad NL, Jain SM. 'Padhar regime' - a low-dose magnesium sulphate treatment for eclampsia. Gynecol Obstet Invest. 2009;67:20-4.

13. Sibai BM. Magnesium sulphate is the ideal anticonvulsant in preeclampsia- eclampsia. Am $\mathbf{J}$ Obstet Gynecol. 1990;162:1141-5.

14. Fernandez FJ, Kahn HL. Clinical method for atomic absorption spectroscopy. Clin Chem Newsl. 1971;3:24-8.

15. Suyajna DJ, Veerendra CM. Single dose MgSO4 regimen for eclampsia - A safe motherhood initiative. J Clin Diagn Res. 2013;7(5):868-72.

16. Dasgupta S, Sarkhel A, Jain A. Single loading dose of magnesium sulphate in severe preeclampsia and eclampsia-is it effective? A randomized prospective study. Obstet Gynecol Int J. 2015;2(6):59.

17. Shohaib T, Khan S, Javed I, Bhutta S. Loading dose of magnesium sulfate versus standard regime for prophylaxis of pre-eclampsia. J Coll Physicians Surg Pak. 2009;19(1):30-3. 
18. Barbieri RL, Repke JT. Maternal disorders during pregnancy. In :Fauci AS, Braunwald E, Kesper DL et al, editors. Harrison's Principles of Internal Medicine, 17th Ed. New York: Mc Graw Hill; 2008:44-49.

19. Tudela CM, McIntire DD, Alexander JM. Effect of maternal body mass index on serum magnesium levels given for seizure prophylaxis. Obstet Gynecol. 2013;121(2 Pt 1):314-20.

20. Biswas A, Modak R, Aksi S, Biswas S, Epidemiological study of eclampsia in a referral teaching hospital. 2005;103(6):323-4.

21. Ekele BA, Muhammed D, Bello LN, Namadina IM. Magnesium sulfate therapy in eclampsia: the Sokoto (ultra short) regimen. BMC Res Notes. 2009;2:165.

22. Hill S, Yang A, Bero L. Priority medicines for maternal and child health: a global survey of national essential medicines lists. PloS One. 2012;7(5):e38055.

23. Suchitra R, Vinuthna NK, Devi S, Bai SK, Begum S. Comparison of low dose, single loading dose and standard Pritchard regimen of magnesium sulphate in antepartum eclampsia. Int $\mathbf{J}$ Current Res. 2015;7(9):20204-07.

24. Regmi MC, Aggrawal A, Pradhan T, Rijal P, Subedi A, Uprety D. Loading dose versus standard regimen of magnesium sulphate in eclampsia - a randomized trial. Nepal Med Coll J. 2010;12:244-7.

25. Begum MR, Begum A, Quadir E. Loading dose versus standard regimen of magnesium sulphate in the management of eclampsia: a randomized trial. J Obstet Gynaecol Res. 2002;28(3):154-9.

Cite this article as: Shreya MS, Nayana DH.

Correlation of serum magnesium levels in eclampsia with pritchard and single dose magnesium sulphate regimen. Int J Reprod Contracept Obstet Gynecol 2019;8:3732-7. 